\title{
EKSPLORASI PERAN PERAWAT DAN AHLI GIZI DALAM PEMBERIAN NUTRISI PADA PASIEN KRITIS
}

\author{
Angela Dwi Pitri", Suhartini Ismail, Meira Erawati \\ Magister Keperawatan Departemen Keperawatan Fakultas Keperawatan UniversitasDiponegoro \\ angela.dp.kay@gmail.com
}

\begin{abstract}
Abstrak
Kesuksesan dukungan nutrisi pasien terletak pada kesinambungan antara terapi obat, perawatan, diet dan peran interdisipliner tim diantaranya perawat dan ahli gizi. Penelitian ini bertujuan untuk menentukan pandangan perawat dan ahli gizi tentang peran mereka dalam gizi. Penelitian kualitatif dengan pendekatan studi fenomenologis yang menghadirkan peran perawat dan ahli gizi dalam mendukung nutrisi pasien kritis melalui sumber informasi dari perawat dan ahli gizi melalui wawancara mendalam dengan teknik wawancara semi-terstruktur.Perawat menyatakan perannya sebagai 1)first line dalam dukungan nutrisi, 2)memaksimalkan asupan makan dengan modifikasi lingkungan, 3)ahli gizi sebagai konselor dan perawat sebagai asesor. Perawat bertanggungjawab agar target nutrisi tercapai meliputi kualitas dan kuantitas. Perannya sebagai first linedidefinisikan sebagai manager yang memiliki otonomi untuk mengatur pengelolaan nutrisi yang didukung oleh faktor lingkungan. Ahli gizi berperan sebagai konselor dan berinteraksi dengan perawat yang memiliki peran sebagai asesor. Perawat dan ahli gizi saling berinteraksi dan saling membutuhkan untuk mencapai satu tujuan ahir sebagai bentukkolaborasi interdisipliner.
\end{abstract}

Kata kunci: peran perawat; peran multidisipliner tim; nutrisi care

\begin{abstract}
Exploration of nurse and nutritional role in nutrition in critical patients. The successful of nutritional support in patients lies in the continuity between drug therapy, patient care, diet and the interdisciplinary role of the team including nurses and nutritionists. This study aims to determine the views of nurses and nutritionists on their role in nutrition. Qualitative research with a phenomenological study approach that presents the role of nurses and nutritionists in nutritional support of critical patients through information sources from nurses and nutritionists through in-depth interviews with semistructured interview techniques. The nurse stated his role as 1) first line in nutritional support, 2) who maximizing food intake with environmental modification, 3) nutritionists as counselors and nurses as assessors. The nurse is responsible for achieving the target nutrition including quality and quantity. The role as first line is defined as a manager who has the autonomy to regulate the management of nutrition supported by environmental factors. Nutritionists act as counselors and interact with nurses who have roles as assessors. Nurses and nutritionists need to interact with each other to achieve an ultimate goal as a form of interdisciplinary collaboration.
\end{abstract}

Keywords: nurse's role; multidisciplinary role of the team; nutrition care

\section{Pendahuluan}

Peningkatan layanan kesehatan saat ini sedang berkembang dengan berfokus menyediakan kualitas layanan yang tinggi. Profesional kesehatan ditantang untuk menyajikan perubahan dalam meningkatkan proses pelayanan. Mencegah serta mengatasi malnutrisi dirumah sakit berpotensiuntuk memaksimalkan kualitas perawatan. Malnutrisi menjadi masalah umum selama perawatan dirumah sakit yang berdampak negatif terutama peningkatan biaya perawatan yang dapat merugikan pasien. Penelitian melaporkan prevalensi tingkat internasional malnutrisi rumah sakit sebanyak $19-60 \%$ angka kejadian. Prevalensi malnutrisi rumah sakit di Australia sebesar 35-63\% dan malnutrisi rumah sakit di indonesia sebesar 61.1\%(Maree, 2011; Sugiarto Nanang, 2014). Sebuah studi di Indonesia melaporkan malnutrisi mendorong peningkatan Length of Stay (LOS) 4-7 hari dengan status malnutrisi 31,8\%, LOS 8-14 hari dengan status malnutrisi $33,7 \%$ dan LOS $\geq 14$ hari dengan status malnutrisi $61,1 \%$.

Malnutrisi berdampak pada emosional dan fisik pasien, dampak fisik 
diantaranya kegagalan fungsi imun, penyembuhan luka yang lama sedangkan dampak emosional yaitu perawatan yang lama dapat meningkatnya biaya perawatan dan menjadi beban bagi pasien(WrightMyrie Donnete, 2013). Mengkonsumsi makanan yang tidak biasa dikonsumsi membuat pasien stres dan tidak nyaman. Penyediaan makanan di rumah sakit sesuai standar dengan pertimbangan keamanan pasien. Pasien kritis biasanya akan diberikan makanan dalam bentuk cair melalui NGT. Pemberian makan dengan NGT tidak seperti proses makan pada umumnya sebab, pasien tidak memasukan makanan melalui mulut, mengunyah dan menelan makanannya. Pasien perlu beradaptasi dengan jenis makanan baru namun, kebutuhan nutrisi pasien kritis tidak dapat ditunda.

Dukungan nutrisi meliputi terapi obat, perawatan, diet dan peran interdisipliner diantaranya dokter, apoteker, ahli gizi dan perawat(Cong et al., 2015; Maree, 2011). Dukungan nutrisi merupakan tugas penting dalam perawatan pasien kritis. Makna nutrisi tidak hanya sebatas makanan masuk ke tubuh pasien. Tetapi, bagaimana makanan dapat memaksimalkan proses penyembuhan pasien. Oleh karena itu, nutrisi pasien kritis dikelola oleh multidisiplin ilmu, diantaranya dokter bertanggungjawab pada seluruh proses pelaksanaan, apoteker bertanggungjawab memberikan terapi obat yang tidak mempengaruhi proses penyerapan makanan, ahli gizi bertanggungjawab menyediakan formula makanan yang tepat sesuai dengan kebutuhan pasien dan perawat bertanggungjawab menyediakan akses masuknya makanan, memaksimalkan penyerapan makanan sampai makanan dihantarkan ke sel tubuh.

Perawat merupakan disiplin ilmu dengan dasar pemikiran bahwa perawatan dilakukan secara komprehensif meliputi kebutuhan bio,psiko,sosio,kultur,spiritual. Perawat memandang pasien merupakahan satu kesatuan untuh, sebab perawat memiliki keyakinan bahwa kebutuhan bio,psiko,sosio,kultur,spiritual saling mempengaruhi satu dengan lainnya. Perawat menggunakan pendekatan asuhan keperawatan untuk mengatasi masalah nutrisi yang tertuang didalam diagnosis keperawatan.

Perawat memandang tiga dasar penting dalam memenuhi kebutuhan nutrisi pasien yaitu(Marjory, 2018); 1)kemampuan memasukan meliputi fungsi digesti mekanis seperti mengunyah dan menelan; 2)kemampuan mencerna meliputi fungsi enzim-enzim pencernaan didalam tubuh untuk membantu pemecahan molekul nutrien menjadi lebih kecil agar bisa diserap oleh usus; 3)kemampuan mengabsopsi yaitu dimulai dari penyerapan sampai menghantarkan zat nutrien ke sel. Fungsi absorpsi meliputi ketersediaan insulin sebagai reseptor glukosa, kemampuan jantung memompa darah dankonsentrasi oksigen yang cukup untuk proses metabolisme zat nutrien sampai membentuk energi(Whitney Ellie, 2008). Sedangkan, Ahli gizi merupakan profesional medis yang berfokus pada aspek kebutuhan gizi penggunaan diet yang tepat, mencegah komplikasi dengan diet yang sesuai serta membantu proses penyembuhan dengan ketersediaan gizi yang cukup.Perawat dan ahli gizi merupakan tenaga profesional yang berasal dari disiplin ilmu berbeda namun, saling bersinggungan dalam tugas pengelolaan nutrisi. Oleh karena itu, perlu dievaluasi seperti apapandangan perawat dan ahli gizi terhadap perannya dalam pemberian nutrisi pada pasien kritis.

\section{Metode}

Penelitian ini dilakukan dengan pendekatan kualitatif studi. Pendekatan kualitatif bermanfaat membantu peneliti menggali informasi terkait peran perawat dan ahli gizi pada perawatan intensif. Data penelitian diambil di ruang ICU rumah sakit umum daerah di kabupaten Semarang Indonesia. Teknik pengumpulan data dengan wawancara mendalam yang 
dilakukan kepada lima perawat dan satu ahli gizi. Wawancara mendalam dilakukan dibeberapa tempat terpisah, dengan durasi wawancara kurang lebih 60 menit. Media bantu peneliti yaitu aplikasi recorder yang tersedia di handphone. Wawancara dipandu kuesioner yang terdiri dari 10 pertanyaan dengan teknik wawancara semiterstruktur.Analisis data menurut panduan interpretive phenomenological analysis (IPA) dengan pendekatan giving voice dan making sence untuk mencapai pemahaman(Noon, 2018).

\section{Hasil}

\section{Data demografi}

Total partisipan 6 orang yang terdiri dari lima orang perawat dan satu orang ahli gizi, rentang lama bekerja 1,5 - 18 tahun, laki-laki $(n=3)$, wanita $(n=3)$ dengan status pendidikan ditingkat sarjana $(\mathrm{n}=5)$ dan tingkat diploma $(n=1)$. Hasil wawancara ditemukan 3 tema, yaitu perawat berperan sebagai; 1) First line dalam dukungan nutrisi, 2) memaksimalkan asupan makan dengan modifikasi lingkungan, 3)Ahli gizi sebagai konselor dan perawat sebagai asesor.

\section{Peran perawat dalam pemberian nutrisi}

Dalam penelitian ini, perawat berpendapat bahwa mereka menjadi manager dalam manajemen nutrisi pasien setiap hari. Perawat melakukan pemeriksaan fisik untuk identifikasi resiko malnutrisi, mengawasi waktu makan pasien, menyediakan akses masuknya makanan dan mengevaluasi makanan yang diserap. First linedigambarkan sebagai kemandirian perawat dalam mengelola managemen nutrisi sesuai dengan peran dan tanggungjawab profesional perawat yang didukung dalam pernyataan perawat sebagai berikut:

“ .....perawat menyediakan data tinggi badan, berat badan untuk menentukan status nutrisi pasien.....perawat mengevaluasi kualitas absorpsi makanan dengan megukur jumlah dan warna residu.....” (P1) “.....perawat mendokumentasikan keadaan umum pasien, tinggi badan, berat badan dan lingkar lengan atas setiap hari dalam catatan keperawatan....."(P3)

“ .....kami mengevaluasi dengan menghitung balance cairan, warna konjungtiva, elastisitas turgor kulit, menimbang berat badan dan lingkar lengan atas.....”(P2)

“.....saya harus memastikan pasien makan sesuai waktu misalnya makan pagi, snack, makan siang dan makan malam.......perawat juga menyediakan akses pemberian makanan melalui Naso Gastric Tube (NGT) atau melalui intravena sesuai advist dokter ...."(P2)

\section{Memaksimalkan asupan makan dengan modifikasi lingkungan}

Perawat menganggappenting untuk menciptakan lingkungan yang mendukung supaya pasien dapat beradaptasi ketika kontak dengan makanan baru. Perawat fokus pada kenyamanan pasien selama pemberian makan, perawat meminimalisir lingkungan yang mengganggu saat makan dan mendorong partisipasi keluarga dalam pemberian makan.

".....perawat memastikan jika makanan yang dikonsumsi tidak membuat mual atau sampai muntah....." (P1)

“ .....kami melakukannya rutin seperti biasa memelihara perawatan diri pasien seperti memandikan agar tubuh tubuh segar, pemeliharaan kebersihan setelah toileting.... pasien merasa senyaman mungkin..... " (P2)

“ .....sebelum diberi makan bisa memposisikan semi fowler agar tidak aspirasi jika makan lewat NGT......menyiapkan meja dan menyingkirkan peralatan yang mengganggu selera makan misalnya urinal atau bedpan di jauhkan....."(P3)

“....perawat dapat mengajarkan kepada keluarga bagaimana cara memberikan makan yang baik dan benar.....meminta bantuan keluarga agar pasien lebih nyaman dan tidak risih atau malu.....” (P4) 
Peran ahli gizi C.S perawat dalam dukungan nutrisi

Ahli gizi sebagai konselor dan perawat sebagai asesor. Ahli gizi berpendapat bahwa mereka memiliki kewenangan terkait segala sesuatu tentang gizi dan perawat berpendapat bahwa dirinya adalah asesor yang bertanggungjawab mengkaji terus menerus untuk mengetahui perubahan status nutrisi pasien.

“ .....kami mengkaji kebutuhan pasien sesuai dengan jenis penyakit dan memiliki kewenangan menghitung kebutuhan nutrisi, menyiapkan nutrisi yang akan dikonsumsi dan menentukan konsistensi formula makanan.....nanti yang memberikan ke pasien itu perawat....."(G1)

" sebagai perawat saya wajib memonitoring setiap shirf seperti keadaan umum seperti edema, pucat, konjungtiva anemis.....apakah tubuh pasien kurus atau bengkak atau mengalami diare kemudian berkonsultasi dengan dokter untuk kolaborasi pemeriksaan laboratorium atau pemberian terapi......"(P1)

“.....saya biasanya menginformasikan bila ada pasien baru dan melaporkan advist formula nutrisi kepada ahli gizi.....”(P2)

\section{Pembahasan}

Perawat sebagai first line dalam dukungan nutrisi

First line didefinisikan sebagai manager bagi profesional perawat perawat,sebagai first lineperawat memiliki otonomi dalam mengelola nutrisi pasien setiap harinya. Pendapat ini sesuai dengan pernyataan bahwa" .....perawat harus memiliki antusiasme sebagai manajer first line yang memiliki keistimewaan dengan pengetahuan sebagai dasar mengambil keputusan dalam merawat serta bertangungjawab...." (Traav Malin Karlberg, 2018). Sebuah pendapat yang menekankan tangggungjawab seorang perawat dalam pengambilan keputusan untuk mengelola nutrisi pasien. Kemampuan pengambilan keputusan dalam pengelolaan nutrisi biasanya dilakukan oleh register nurses yang telah dibekali pengetahuan dan memiliki pengalaman mengelola nutrisi.Pendapat lain diungkapkan oleh Bloomer mengenaitugas perawat sebagaicare, maintenance dan manajemen selama proses mengelola nutrisi pasien. Pernyataan ini didukung dalam penelitian Bloomer yang berpendapat bahwa ".....perawat memastikan pasien mendapatkan makanan kurang dari 24 jam pertama dirawat.....memasang NGT, memulai pemberian makan, memonitoring makanan yang diserap serta memantau target nutrisi.....memaksimalkan penyerapan makanan bersamaan dengan proses titrasi obat-obatan seperti sedasi yang mempengaruhi fungsi absorpsi usus....."(Bloomer Melissa J, 2017). Pendapat Bloomer menyempurnakan pemahaman perawat sebagai first line dalam mengelola nutrisi, bahwa tugas perawat sangat kompleks sesuai dengan dasar pemikiran bahwa kebutuhan nutrisi meliputi kemampuan memasukan, mencerna, mengabsopsi serta menghantarkan zat nutrien sampai menghasilkan energi(Tappenden et al., 2013).

\section{Perawat memaksimalkan asupan makan dengan modifikasi lingkungan}

Setiap individu memiliki makanan kesukaan, cara mengolah makanan dan kebiasaan yang berbeda-beda. Makanan dirumah sakit seringnya membuat pasien stres karena tidak terbiasa dan membuat nafsu makan pasien berkurang ditambah lagi proses penyakit yang dapat mempengaruhi fungsi pencernaan. Pasien kritis memiliki proses penyembuhan yang kompleks karena proses penyakit yang membutuhkan banyak energi untuk mempertahankan hemodinamik. Tujuan perawat dalam mengelola nutrisi pasien kritis adalah target nutrisi tercapai yang meliputi kualitas dan kuantitas. Perawat berusaha memodifikasi lingkungan untuk mendukung asupan makan. Pernyataan ini 
didukung oleh Dickinson dalam penelitiannya yang menyatakan "....ketika saya tidak bisa memotong makanan, perawat akan membantu saya....tapi saya masih memiliki hak diriku sendiri dan tidak mengganggu siapa pun.....saya pikir bagus bila perawat benar-benar menunggu saya....saya terbiasa menunggu perawat hadir didepan saya dan itu terasa indah....."(Dickinson Angela, 2008).

Pernyataan pasien ini menunjukan bahwa mereka menikmati kehadiran perawat dan memberi rasa nyaman dan bahagia, sebuah perasaan yang kental akan keterikatan emosi antara perawat dan pasien akan menciptakan kepercayaan antara perawat dan pasien. Kepercayaan ini akan mendukung tujuan perawat untuk mencapai target nutrisi yang diinginkan(Laur Celia, 2017). Selain itu, perawat juga berpendapat bahwa menciptakan lingkungan untuk mendukung pasien makan adalah dengan melibatkan keluarga. Pernyataan ini dituliskan dalam penelitian “...saya berpikir keluarga memiliki peran penting, mereka mengatakan apa yang mereka inginkan dan apa yang tidak... saya mengamati bahwa itu berhasil ketika mereka memberi minum kepada pasien ...ayolah....ini baik untuk kamu...dan kamu tahu mereka mencoba melakukannya ketika anaknya yang memberikan.....". Keluarga merupakan sosok yang memiliki kedekatan emosi dengan pasien sehingga membangun semangat pasien untuk makan. Oleh karena itu, perawat perlu mengajarkan kepada keluarga bagaimana cara memberikan makan dan minum yang aman pada pasien kritis(Maree, 2011).

\section{Ahli gizi sebagai konselor dan perawat sebagai asesor}

Peran Konselor seorang ahli gizi

Peran ahli gizi sebagai konselor ditekankan pada peran pendampingan pasien dalam menentukan atau memilih jenis makanan yang disukai pasien. Ahli gizi dengan pasien terjadi interaksi berupa konsultasi terkait diet berdasarkan jenis penyakit pasien(Roberts S, 2014). Kehadiran ahli gizi dipercaya mempengaruhi psikologis pasien dan membantu membangun lingkungan yang mendukung asupan makan pasien. Pernyataan ini didukung sebuah penelitian yang melaporkan “.....kami menyarankan berbagai jenis makanan, berdasarkan berbagai macam makanan menurut panduan.....kami bekerjasama dengan pasien mencoba untuk mengatur jenis makanan ringan, buah-buahan dan makanan berat. Misalnya seperti sepotong melon, yogurt, sup krim sederhana yang dikemas porsi kecil tetapi sering.....ada juga upaya seperti melibatkan keluarga dalam konseling untuk menjelaskan strategi diet seperti pantangan atau makanan yang dihindari, sehingga mereka tahu bagaimana mendukung pasien...(ahli gizi)(FI Pinto, 2016; Henning, 2009).

Peran asesor seorang perawat

Peran asesor merupakan tugas mengkaji atau assesment, perawat melakukannya berulang-ulang serta terus menerus dan tercatat didalam catatan perawat untuk mengidentifikasi adanya perubahan status nutrisi atau resiko mengalami malnutrisi. Pernyataan ini didukung oleh penelitian yang melaporkan " ...perawat mengelola pasien berdasarkan guideline untuk mengamati respon tubuh pasien terhadap makanan, menentukan target waktu, mengelola residu makanan dan mengkontrol konsentrasi glukosa pasien....perawat melaporkan kemampuan absorpsi pasien...kami bertanya dan bernegosiasi dengan profesi lain untuk memutuskan jenis makanan yang akan dipesan.....(register nurses)(Bloomer Melissa J, 2017). Bila menemukan resiko mengalami malnutrisi perawat akan bertanya serta bernegosiasi dengan profesi lain untuk menentukan jenis makanan yang akan dipesan. oleh karena itu, sangat penting bagi perawat memiliki pengalaman dan pengetahuan untuk meningkatkan kualitas perawatan nutrisi pasien $(\mathrm{Xu}$ Xiaoyue, 2017). 
Peran perawat sebagai asesor digambarkan dalam pengkajian yang dilakukan berulang-ulang untuk menemukan perubahan pada status nutrisi pasien. Perawat juga bernegosiasi dengan ahli gizi dalam penentuan jenis makanan lain yang mungkin aman untuk meningkatkan status nutrisi pasien. Proses konsultasi dan negosiasi ini menunjukan peran ahli gizi sebagai konselor. Hubungan timbal balik antara perawat dan ahli gizi ini disebut dengan peran interdisipliner. Oleh karena itu, perawat dan ahli gizi saling berinteraksi dan saling membutuhkan untuk mencapai satu tujuan yaitu kesejahteraan nutrisi pasien.

\section{Simpulan dan Saran}

Perawat bertanggungjawab agar target nutrisi tercapai yang meliputi kualitas dan kuantitas Perawat berperan sebagai first line merupakan gambaran seorang manager yang memiliki otonomi dalam mengatur diri sendiri mengelola nutrisi. Perawat memaksimalkan asupan nutrisi dengan memodifikasi lingkungan membuat pasien senyaman mungkin serta melibatkan keluarga, kemudian perawat sebagai asesor berinteraksi dengan ahli gizi sebagai konselor. Perawat danahli gizi saling berinteraksi dan saling membutuhkan untuk mencapai satu tujuan ahir didefinisikansebagaikolaborasi interdisipliner.

\section{Daftar Pustaka}

Bloomer, M. J., Clarke, A. B., \& Morphet, J. (2017). Nurses prioritization of enteral nutrition in intensive care units : a national survey. Nurs Crit Care.23(3):152-158.

Cong, M. H., Li, S. L., Cheng, G. W., Liu, J. Y., Song, C. X., Deng, Y. B., ... $\mathrm{Yu}, \mathrm{L}$. (2015). An interdisciplinary nutrition support team improves clinical and hospitalized outcomes of esophageal cancer patients with concurrent chemoradiotherapy. Chin Med J, 20;128(22):3003-7.
Dickinson Angela, et al. (2008). No longer hungry in hospital: Improving the hospital mealtime experience for older people through action research. J Clin Nurs, 17(11), 1492-1502.

Whitney Ellie R S. (2008). Understanding nutrition. (Vol. 8). Wadsworth Publishing, 1-878 p.

FI Pinto, et al. (2016). The Dietitian's Role in Palliative Care: A Qualitative Study Exploring the Scope and Emerging Competencies for Dietitians in Palliative Care. J Palliat Care Med, $06(02) ; 2-8$.

Henning, M. (2009). Nursing' s Role in Nutrition. Comput Inform Nurs.27(5), 301-306.

Laur Celia, et al. (2017). Changing nutrition care practices in hospital: A thematic analysis of hospital staff perspectives. BMC Health Services Research,17(1), 1-15.

Maree, J. D. \& J. (2011). Nurturing and nourishing: The nurses' role in nutritional care. J Clin Nurs,20(3-4), 317-330.

Marjory, G. (2018). Nursing Diagnosis Definisions and clasification 20182020.

Noon, E. J. (2018). Interpretive Phenomenological Analysis: An Appropriate Methodology for Interpretive Phenomenological Analysis: An Appropriate Methodology for Educational Research. JPAAP, 6 (1); 75-83.

Roberts S, et al. (2014). Patient perceptions of the role of nutrition for pressure ulcer prevention in hospital: An interpretive study. J Wound Ostomy Conlinence Nurs, 41(6), 528534. 
Sugiarto Nanang, et al (2014). The Factors Affecting the Length of Stay in the Intensive Care Units of Pertamina Central Hospital in Indonesia Related to Healthcare Associated Infections. Journal of US-China Medical Science, 11, 195-204.

Tappenden, K. A., Quatrara, B., Parkhurst, M. L., Malone, A. M., Fanjiang, G., \& Ziegler, T. R. (2013). Critical Role of Nutrition in Improving Quality of Care. JPEN J Parenter enteral Nutr, 37(4), 482-497.

Traav Malin Karlberg, et al. (2018). First line nurse managers' experiences of opportunities and obstacles to support evidence-based nursing. Nurs Open,5(4), 634-641.

Wright-Myrie Donnete, et al. (2013). Nutrition in critical illness : Critical care nurses ' knowledge and skills in the nutritional management of adults requiring intensive care $-A$ review of the literature management of adults requiring intensive care $-\mathrm{A}$ review of the literature. Caribbean Journal of Nursing. 1(1);49-55

$\mathrm{Xu}$ Xiaoyue, et al. (2017). Where is the nurse in nutritional care. Contemporary Nurse,53(3), 267-270. 
Jurnal Perawat Indonesia, Volume 3 No 2, Hal 109-116, Agustus 2019 Persatuan Perawat Nasional Indonesia Jawa Tengah 